\title{
Cardiopulmonary bypass time is an independent risk factor for acute kidney injury in emergent thoracic aortic surgery: a retrospective cohort study
}

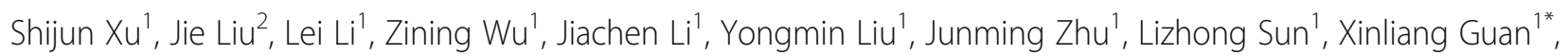
Ming Gong ${ }^{1 *}$ and Hongjia Zhang ${ }^{1 *}$

\begin{abstract}
Background: Thoracic aortic surgery and cardiopulmonary bypass are both associated with development of postoperative acute kidney injury. In this study, we undertook to investigate the relationship between cardiopulmonary bypass time and postoperative acute kidney injury in patients undergoing thoracic aortic surgery for acute DeBakey Type I aortic dissection.

Methods: All patients receiving thoracic aortic surgery for acute DeBakey Type I aortic dissection in Beijing Anzhen hospital from December 2015 to April 2017 were included. Cardiopulmonary bypass time was recorded during surgery. Acute kidney injury was defined based on the Kidney Disease Improving Global Outcomes criteria. A total of 115 consecutive patients were eventually analyzed.

Results: The overall incidence of acute kidney injury was $53.0 \%(n=61)$. The average age was $47.8 \pm 10.7$ years; 74 . $8 \%$ were male. Mean cardiopulmonary bypass time was $211 \pm 56 \mathrm{~min}$. In-hospital mortality was $7.8 \%$. Multivariate logistic regression revealed that cardiopulmonary bypass time was independently associated with the occurrence of postoperative acute kidney injury after adjust confounding factors (odds ratio $=1.171 ; 95 \%$ confidence interval: 1 . 002-1.368; $P=0.047$ ).

Conclusions: Cardiopulmonary bypass time is independently associated with an increased hazard of acute kidney injury after thoracic aortic surgery for acute DeBakey Type I aortic dissection. Further understanding of the mechanism of this association is crucial to the design of preventative strategies.
\end{abstract}

Keywords: Acute kidney injury, Aortic dissection, Cardiopulmonary bypass, Risk factor, Thoracic aortic surgery

\section{Introduction}

Acute kidney injury (AKI) is frequent as a serious complication following operation for acute DeBakey Type I aortic dissection (ADTIAD). But, the reported incidence of AKI following operation for ADTIAD varies extensively (20 to 67\%), because the definition of AKI is

\footnotetext{
*Correspondence: guanx1119@sina.com; gongmaster@126.com;

zhanghongjia722@ccmu.edu.cn

'Department of Cardiac Surgery, Beijing Aortic Disease Center, Beijing Anzhen Hospital, Capital Medical University, Beijing Institute of Heart Lung and Blood Vessel Diseases, Beijing Lab for Cardiovascular Precision Medicine, and Beijing Engineering Research Center of Vascular Prostheses, No.2 Anzhen Street, Beijing 100029, China

Full list of author information is available at the end of the article
}

different among studies, which is mildly higher than the incidences following other cardiac operations $[8,34,36$, $38,40]$. Furthermore, 2 to $8 \%$ of patients need renal replacement therapy (RRT) following aortic surgery [1, 2, $9,10,19,20]$, which is related to an elevated short-term death rate of up to $64 \%[6,10,19,20]$. Previous studies had found that even mild AKI following cardiothoracic surgery would aggravate short-term outcomes such as 30 - or 90-day mortality, morbidity, and cost [9, 21, 29]. As no efficient therapy for AKI is available currently [35], identifying risk factors and preventing AKI following cardiothoracic surgery are necessary parts of improving outcomes [7]. 
Cardiopulmonary bypass $(\mathrm{CPB})$ is necessary to facilitate surgical correction of ADTIAD. However, it can result in significant inflammation and oxidant stress response which contribute to multi-organ dysfunction. Studies examining the association between $\mathrm{CPB}$ time and postoperative AKI in patients undergoing thoracic aortic surgery for ADTIAD have not been extensive.

For these reasons, we conducted a retrospective cohort study to investigate the relationship between $\mathrm{CPB}$ time and AKI in patients who underwent thoracic aortic procedure for ADTIAD using a multivariate logistic regression model containing all known associated major perioperative predictors. Our hypothesis was that the risk of AKI would increase as CPB time increased.

\section{Methods}

\section{Participants}

A retrospective cohort study was conducted at the Beijing Anzhen hospital from December 2015 to April 2017 in China, Beijing. This study was approved by the ethics committees of this hospital and conducted following the rules of Good Clinical Practice and principles of the Declaration of Helsinki. Individual consent was waived owing to the retrospective study. All patients who underwent aortic total arch replacement (TAR) combined with a frozen elephant trunk (FET) implant for ADTIAD in this timeframe were included. All operations were performed by the identical surgery team.

\section{Data collection}

Trained staff collected detailed data from recruited patients from the electronic medical records at our medical center. The baseline characteristics collected for each patient involved age, gender, height, weight, body mass index (BMI, calculated based on height and weight recorded by the nurse on the day of hospital admission), drinking history, smoking history; Comorbidities: diabetes mellitus, hypertension, previous cerebrovascular disease, left ventricular ejection fraction (LVEF), coronary artery disease, preoperative hemoglobin, hematocrit, preoperative serum creatinine $(\mathrm{sCr})$, preoperative blood urea nitrogen (BUN); eGFR (estimated glomerular filtration rate, calculated based on Epidemiology Collaboration equation), hemopericardium, renal artery dissection or occlusion, Penn class (Class Aa and Non class $\mathrm{Aa}$ ), kidney malperfusion, acute myocardial infarction (AMI), preoperative shock; Intraoperative data: intraoperative transfusion of packed red blood cells (PRBCs), CPB time, aortic cross clamp time, circulatory arrest time, rectal temperature at circulatory arrest, nasopharyngeal temperature at circulatory arrest, the type of surgery (Bentall+TAR+FET or ascending aorta replacement+TAR+FET), combined with coronary artery bypass grafting (CABG) and combined with ascending aorta to femoral artery bypass surgery (aortic bypass surgery); Postoperative data: reoperation for bleeding, postoperative dialysis, length of intensive care unit (ICU) stay, length of time in hospital, sepsis, in-hospital death. It should be noted that in our study cohort, there was no patient underwent coronary angiography (CAG) within the $24 \mathrm{~h}$ before surgery and no patient received aprotinin or underwent statin therapy. Primary indications for postoperative dialysis were volume overload, uremia, anuria, and significant biochemical abnormalities.

The presence or absence of malperfusion was based on the Penn classification which was established and subsequent validated in the last decade [31]. Preoperative shock was defined as a systolic blood pressure $<90$ $\mathrm{mmHg}$ [11]. Patients with ST elevation on a 12-lead electrocardiogram associated with wall hypokinesis at the corresponding region on echocardiography were considered to have AMI [33]. Renal malperfusion was diagnosed as at least one renal artery dissection with creatinine rise above $50 \%$ of the normal upper limit [11].

\section{Outcome variables}

The primary endpoint event was AKI after thoracic aortic surgery for ADTIAD. Several classification criterions were established to access the postoperative AKI. Recently, KDIGO put forward a new range of guidelines for the classification of postoperative AKI based on the 2 previous classifications, RIFLE and AKIN [15, 24]. For the purpose of this study, postoperative AKI was diagnosed based on the KDIGO criteria: increase in $\mathrm{sCr} \geq$ $0.3 \mathrm{mg} / \mathrm{dL}$ (in $48 \mathrm{~h}$ ) or 1.5 times or greater by baseline (in 7 days).

\section{Assessment of covariates}

Age, gender, diabetes mellitus, hypertension, preoperative hemoglobin, hematocrit, preoperative $\mathrm{sCr}$, preoperative BUN, eGFR, renal artery dissection or occlusion, Penn class, kidney malperfusion, AMI, preoperative shock, CPB time, aortic cross clamp time, circulatory arrest time, nasopharyngeal temperature at circulatory arrest, rectal temperature at circulatory arrest, reoperation for bleeding were recorded in all participants. Preoperative $\mathrm{sCr}, \mathrm{BUN}$, hemoglobin, hematocrit was recorded based on the results of the initial laboratory test after admission before surgery.

\section{Surgical technique}

Patients underwent median sternotomy and CPB. Briefly, the procedure is performed with right axillary artery cannulation for $\mathrm{CPB}$ and antegrade cerebral perfusion $[5-15 \mathrm{~mL} /(\mathrm{kg} \cdot \mathrm{min})]$ under moderate hypothermic circulatory arrest (HCA). CPB was performed after systemic heparinization $[300 \mathrm{U} / \mathrm{kg}$ and maintaining an activated 
clotting time (ACT) longer than $480 \mathrm{~s}]$. Temperature-adjusted flow rates were $2.5 \mathrm{~L} /\left(\mathrm{min} \cdot \mathrm{m}^{2}\right)$ at the time of $\mathrm{CPB}$. The mean arterial pressure was commonly maintained between 50 and $70 \mathrm{mmHg}$. After CPB was established, cooling was initiated. After clamping of the ascending aorta, cardiac arrest was accomplished with cold cardioplegic solution. Whether to perform an aortic valve replacement depended on the condition of the aortic valve. If the classification of aortic regurgitation was moderate or severe, we preferred to perform Bentall procedure (aortic valve replacement combined with ascending aorta replacement). If there was only mild regurgitation, we preferred to perform ascending aorta replacement only. All patients underwent TAR with FET. The method has been described in detail by our research team $[26,37]$. An intraoperative stent-graft (MicroPort Medical Company Limited, Shanghai, China) and a four branched prosthetic graft (Maquet Cardiovascular, Wayne, NJ) were employed in this implantation. In brief, cannulation of the right axillary artery was used for $\mathrm{CPB}$ and unilateral selective cerebral perfusion (SCP). The distal aorta was transected circumferentially between the origin of the left common carotid artery and the origin of the left subclavian artery. The stent was implanted into the distal aorta. The distal aorta incorporating the stented elephant trunk was firmly attached to the distal end of the four-branched prosthetic graft using the "open" aortic method. Antegrade systemic perfusion was reestablished through the perfusion limb of the four-branched prosthetic graft. The anastomosis to the left common carotid artery was carried out first. After the anastomosis was completed, CPB was gradually returned to normal flow, SCP was discontinued, and rewarming was started. The anastomosis to the left subclavian artery, the innominate artery, and the proximal anastomosis were completed. If the blood pressure of the upper and lower limbs differed significantly and the signs and symptoms of lower limbs ischemia were presented, the ascending aorta to femoral artery bypass surgery was performed.

\section{Sample size}

After excluding the 22 patients, a total of 115 consecutive patients underwent TAR combined with a FET implant for ADTIAD were included in the final analysis.

\section{Statistical analysis}

Continuous variables were provided as median (quartile) or mean \pm standard deviation (SD), in the light of the data dispersion. Categorical variables were expressed as percentages (\%). The t-tests were used to compare if the continuous variables followed normal distribution, and if the variables were skewed distribution, non-parametric Mann-Whitney U tests were applied. The chi-square test was applied to compare with categorical variates. Logistic regression analysis was applied to identify the predictors of postoperative AKI. Multiple logistic regression analysis was used to evaluate the association between $\mathrm{CPB}$ time and postoperative AKI. We constructed four models: (I) adjusted for none; (II) adjusted for demographics: age; gender; (III) adjusted for age; gender; BMI; smoking history; aortic cross clamp time; nasopharyngeal temperature at circulatory arrest; combined with aortic bypass surgery; AMI; intraoperative transfusion of PRBCs; (IV) adjusted for age; gender; BMI; smoking history; aortic cross clamp time; nasopharyngeal temperature at circulatory arrest; combined with aortic bypass surgery; AMI; intraoperative transfusion of PRBCs; renal artery dissection or occlusion; Penn class; kidney malperfusion; preoperative shock; Bentall+TAR + FET. Conforming to the recommendations of the STROBE statement [39], the results were analyzed from unadjusted or minimally adjusted and fully adjusted in parallel. Whether the covariables was adjusted was determined according to the recommendations of the article published by The NEW ENGLAND JOURNAL of MEDICINE [16]: if, when the variable was added to this model, the matched odds ratio was changed by at least $10 \%$ then an adjustment was made. In addition, a generalized additive model (GAM) was also applied to identify linear relationships. The propensity score (PS) matching method was used to adjust intergroup differences between the non-AKI and AKI groups. We calculated the PS for each patient by matching variables (age; gender; BMI; diabetes mellitus; hypertension; smoking history; BUN; preoperative sCr; hemoglobin; hematocrit; eGFR). The balance in baseline covariant was assessed through paired t-tests and McNemar tests and standardized the mean differences as appropriate for categorical and continuous variables.

Interaction and stratified analysis were performed based on age ( $<60$ and $\geq 60$ years), gender, BMI $(<24 \mathrm{~kg} /$ $\mathrm{m}^{2}, 24-28 \mathrm{~kg} / \mathrm{m}^{2}, \geq 28 \mathrm{~kg} / \mathrm{m}^{2}$ ), hypertension, drinking history, smoking history, coronary artery disease, eGFR (< $60 \mathrm{~mL} / \mathrm{min} / 1.73 \mathrm{~m}^{2}, \geq 60 \mathrm{~mL} / \mathrm{min} / 1.73 \mathrm{~m}^{2}$ ), aortic cross clamp time $(<115 \mathrm{~min}, \geq 115 \mathrm{~min})$, circulatory arrest time ( $<27 \mathrm{~min}, \geq 27 \mathrm{~min})$, hemoglobin $(<135 \mathrm{~g} / \mathrm{L}, \geq 135$ $\mathrm{g} / \mathrm{L}$ ). All of the analysis was performed with the statistical software packages R (http://www.R-project.org, The $\mathrm{R}$ Foundation) and Empower Stats (http://www.empowerstats.com, X\&Y Solutions, Inc., Boston, MA). A 2-sided significance level of 0.05 was regarded as statistically significant.

\section{Results}

\section{Patients and inclusion characteristics}

A total of 137 consecutive patients with ADTIAD who underwent emergent aortic TAR combined with an FET 
implant with CPB were included. All aortic TAR combined with a FET implant procedure, with or without aortic valve operation, were eligible. A total of 18 patients requiring RRT before surgery were excluded for the difficulty to evaluate the progression of renal dysfunction and three patients who died intraoperatively or within $24 \mathrm{~h}$ after operation were also excluded because no useful data were available to evaluate the AKI. One patient was excluded for incomplete information. As a consequence, a total of 115 consecutive persons were included in the eventual analysis. A flow chart of the screening and registration of study participants was given in Fig. 1 .

\section{Characteristics of the study patients at baseline}

After the exclusion criteria were used, 115 consecutive patients were admitted to this cohort. The average age was $47.8 \pm 10.7$ years. There were $86 \quad(74.8 \%)$ male among these patients. The overall incidence of AKI was $53.0 \%$ (61 patients). The average CPB time was $211 \pm 56$ $\mathrm{min}$. The average preoperative $\mathrm{sCr}$ was $86.2 \pm 29.1 \mathrm{umol} /$ $\mathrm{L}, \mathrm{BUN}$ was $7.2 \pm 2.5 \mathrm{mmol} / \mathrm{L}$. The average eGFR was $88.6 \pm 22.6 \mathrm{~mL} /\left(\mathrm{min} \cdot 1.73 \mathrm{~m}^{2}\right)$, Hemoglobin was $136.5 \pm$ $17.3 \mathrm{~g} / \mathrm{L}$. The incidence of sepsis was $14.8 \%$. A total of 23 patients required RRT. In-hospital mortality was $7.8 \%$. The characteristics of the 115 patients at baseline who underwent thoracic aortic surgery for ADTIAD were shown in Table 1.

\section{Univariate analysis of risk factors associated with postoperative acute kidney injury in patients with ADTIAD}

The consequences of a univariate analyses were given in Table 2. These results revealed that BMI, eGFR and CPB time were all correlated with AKI. We also found smoking, drinking, preoperative hemoglobin levels, history of diabetes mellitus, hypertension, coronary artery disease, preoperative hematocrit, preoperative $\mathrm{sCr}$, BUN, LVEF, renal artery dissection, Penn class, kidney malperfusion, coronary malperfusion, preoperative shock, aortic cross clamp time, circulatory arrest time and Bentall+TAR +FET were not associated with AKI.

\section{The linear relationship between CPB time and AKI after adjusting for covariates}

Spline smoothing was applied using GAM to explore the association between $\mathrm{CPB}$ time and AKI after adjusting for age; gender; BMI; smoking history; aortic cross clamp time; nasopharyngeal temperature at circulatory arrest; combined with aortic bypass surgery; AMI; intraoperative transfusion of PRBCs; renal artery dissection or occlusion; Penn class; kidney malperfusion; preoperative shock; Bentall+TAR+FET. A linear relationship between CPB time and AKI was shown in Fig. 2. The red points express the fitting spline. The black points express the $95 \%$ confidence intervals.

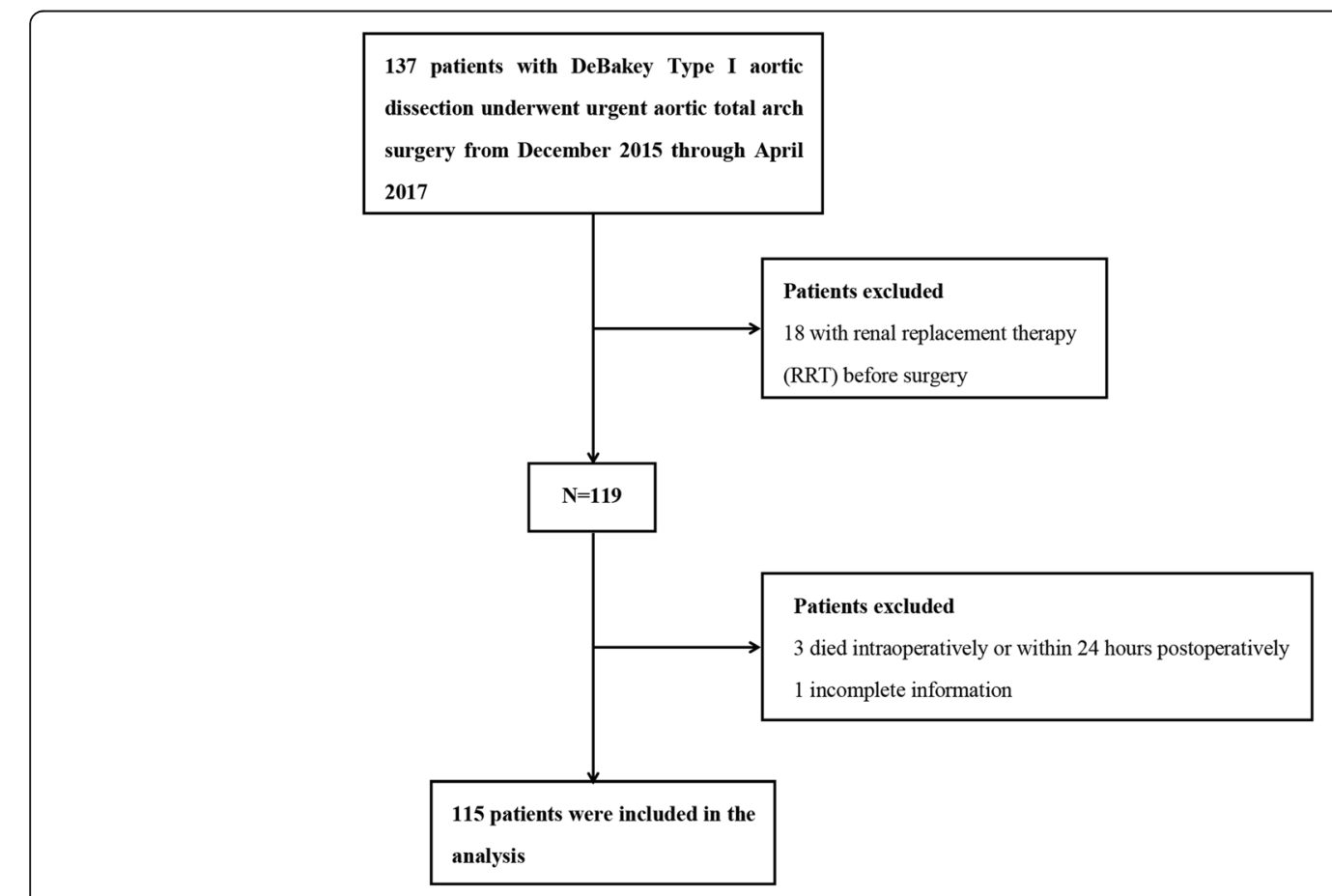

Fig. 1 Flow diagram of the screening and enrollment of study patients 
Table 1 Characteristics of the study patients at baseline

\begin{tabular}{|c|c|}
\hline Variables & All patients $(n=115)$ \\
\hline Age (year) & $47.8 \pm 10.7$ \\
\hline \multicolumn{2}{|l|}{ Gender } \\
\hline male & 86 (74.8\%) \\
\hline female & $29(25.2 \%)$ \\
\hline $\mathrm{BMI}\left(\mathrm{kg} / \mathrm{m}^{2}\right)$ & $26.2 \pm 3.9$ \\
\hline Diabetes mellitus & $7(6.1 \%)$ \\
\hline Hypertension & $92(80.0 \%)$ \\
\hline Previous cerebrovascular disease & $6(5.2 \%)$ \\
\hline Coronary artery disease & $6(5.2 \%)$ \\
\hline Smoking history & $56(48.7 \%)$ \\
\hline Drinking history & $23(20.0 \%)$ \\
\hline Hemopericardium & $19(16.5 \%)$ \\
\hline BUN (mmol/L) & $7.2 \pm 2.5$ \\
\hline Preoperative $\mathrm{sCr}$ (umol/L) & $86.2 \pm 29.1$ \\
\hline eGFR mL/(min.1.73m²) & $88.6 \pm 22.6$ \\
\hline Hemoglobin (g/L) & $136.5 \pm 17.3$ \\
\hline Hematocrit (\%) & $39.4 \pm 4.6$ \\
\hline LVEF (\%) & $62.9 \pm 6.0$ \\
\hline Renal artery dissection or occlusion & $17(14.8 \%)$ \\
\hline \multicolumn{2}{|l|}{ Penn class } \\
\hline Class Aa & $70(60.9 \%)$ \\
\hline Non class $\mathrm{Aa}$ & $45(39.1 \%)$ \\
\hline Kidney malperfusion & $7(6.1 \%)$ \\
\hline AMl & $9(7.8 \%)$ \\
\hline Preoperative shock & $19(16.5 \%)$ \\
\hline CPB time (min) & $211 \pm 56$ \\
\hline Aortic cross clamp time (min) & $123.8 \pm 42.6$ \\
\hline Circulatory arrest time (min) & $27.4 \pm 8.5$ \\
\hline Bentall+TAR+FET & 47 (40.9\%) \\
\hline Combined with CABG & $8(7.0 \%)$ \\
\hline Combined with aortic bypass surgery & $1(0.9 \%)$ \\
\hline Nasopharyngeal temperature $\left({ }^{\circ} \mathrm{C}\right)$ at circulatory arrest & $22.9 \pm 1.6$ \\
\hline Rectal temperature $\left({ }^{\circ} \mathrm{C}\right)$ at circulatory arrest & $25.3 \pm 2.1$ \\
\hline Intraoperative transfusion of PRBCs & $73(63.5 \%)$ \\
\hline AKI & $61(53.0 \%)$ \\
\hline Reoperation for bleeding & $9(7.8 \%)$ \\
\hline Postoperative dialysis & $23(20.0 \%)$ \\
\hline Sepsis & $17(14.8 \%)$ \\
\hline Length of in hospital (day) & $14.0(10.0-18.0)$ \\
\hline Length of ICU (day) & $3.0(1.0-6.2)$ \\
\hline In-hospital mortality & $9(7.8 \%)$ \\
\hline
\end{tabular}

Results are expressed as $n(\%)$ or mean \pm SD or median [IQR] $A K l$ acute kidney injury, $A D T I A D$ acute DeBakey Type I aortic dissection, $A M I$ acute myocardial infarction, $B M I$ body mass index, $B U N$ blood urea nitrogen, $C A B G$ coronary artery bypass grafting, $C P B$ cardiopulmonary bypass, eGFR estimated glomerular filtration rate, FET frozen elephant trunk, TAR total arch replacement, ICU intensive care unit, LVEF left ventricular ejection fraction, $P R B C s$ packed red blood cells, $s C r$ serum creatinine, $S D$ standard deviation, IOR interquartile range
Multivariable analysis to assess the independent impact of CPB time on postoperative AKI in patients with ADTIAD using non-adjusted and adjusted logistic regression model

Table 3 revealed the results of multivariate logistic regression analysis models for AKI based on different variable categories (preoperative, intraoperative and variables which are known to be related to AKI) included in each analysis. In adjusted model I, the result showed a significant association between CPB time and AKI [odds ratio $(\mathrm{OR})=1.085 ; 95 \%$ confidence interval (CI): 1.007-1.170; $P=0.033$ ]. In adjusted model II (adjusted age; gender), the result remained significant (OR $=1.092$, 95\% CI:1.012-1.179; $P=0.024)$. In adjusted model III (adjusted age; gender; BMI; smoking history; aortic cross clamp time; nasopharyngeal temperature at circulatory arrest; combined with aortic bypass surgery; $\mathrm{AMI}$; intraoperative transfusion of $\mathrm{PRBCs}$ ), the result remained significant $(\mathrm{OR}=1.166,95 \% \mathrm{CI}: 1.009-1.349 ; P$ $=0.031$ ). In adjusted model IV (adjusted for age; gender; BMI; smoking history; aortic cross clamp time; nasopharyngeal temperature at circulatory arrest; combined with aortic bypass surgery; AMI; intraoperative transfusion of PRBCs; renal artery dissection or occlusion; Penn class; kidney malperfusion; preoperative shock; Bentall+TAR + FET.), the result still remained significant $(\mathrm{OR}=1.171$; 95\% CI:1.002-1.368; $P=0.047)$.

\section{Sensitivity analysis using PS matching}

To reduce the influence of confounding variables, we subsequently utilized the derived PS values to match 61 patients in the AKI group with the patients in the non-AKI group at a ratio of 1:1 using a greedy matching algorithm [4]. Finally, 64 patients were successfully matched, 32 patients with AKI and 32 without AKI. After all PS matches were performed, all variables were shown in Additional file 2: Table S1. The PS matching map was shown in Additional file 1: Figure S1. After PS matching ( $n=64$ pairs), the association between $\mathrm{CPB}$ time and AKI was still statistic significant $(\mathrm{OR}=1.128$, 95\% CI:1.004-1.267; $P=0.043)$. The results were shown in Additional file 3: Table S2.

\section{Stratified analysis}

Stratified analysis was performed in patients with age $(<$ 60 and $\geq 60$ years $)$, gender, BMI $\left(<24 \mathrm{~kg} / \mathrm{m}^{2}, 24-28 \mathrm{~kg} /\right.$ $\mathrm{m}^{2}$, $\left.\geq 28 \mathrm{~kg} / \mathrm{m}^{2}\right)$, hypertension, smoking history, drinking history, coronary artery disease, eGFR $(<60 \mathrm{~mL} / \mathrm{min} /$ $\left.1.73 \mathrm{~m}^{2}, \geq 60 \mathrm{~mL} / \mathrm{min} / 1.73 \mathrm{~m}^{2}\right)$, aortic cross clamp time (<115 $\mathrm{min}, \geq 115 \mathrm{~min}$ ), circulatory arrest time $(<27 \mathrm{~min}$, $\geq 27 \mathrm{~min}$ ), hemoglobin $(<135 \mathrm{~g} / \mathrm{L}, \geq 135 \mathrm{~g} / \mathrm{L})$. CPB time was still an independent predictor of post-operation AKI in one of these high-risk subgroups. And, there was no 
Table 2 Univariate analysis of risk factors associated with postoperative AKI in patients with ADTIAD

\begin{tabular}{|c|c|c|c|}
\hline Variable & Statistics & OR $(95 \% \mathrm{Cl})$ & $P$-value \\
\hline Age (year) & $47.8 \pm 10.7$ & $1.02(0.98,1.05)$ & 0.339 \\
\hline \multicolumn{4}{|l|}{ Gender } \\
\hline male & $86(74.78 \%)$ & 1.0 & \\
\hline female & $29(25.22 \%)$ & $1.35(0.58,3.17)$ & 0.487 \\
\hline BMI $\left(\mathrm{kg} / \mathrm{m}^{2}\right)$ & $26.2 \pm 3.9$ & $1.18(1.06,1.33)$ & 0.003 \\
\hline Diabetes mellitus & 7 (6.09\%) & $5.78(0.67,49.62)$ & 0.110 \\
\hline Hypertension & $92(80.00 \%)$ & $1.30(0.52,3.24)$ & 0.576 \\
\hline Previous cerebrovascular disease & $6(5.22 \%)$ & $0.42(0.07,2.41)$ & 0.333 \\
\hline Coronary artery disease & $6(5.22 \%)$ & $0.88(0.17,4.55)$ & 0.878 \\
\hline Smoking history & $56(48.70 \%)$ & $1.83(0.87,3.85)$ & 0.110 \\
\hline Drinking history & $23(20.00 \%)$ & $0.96(0.38,2.39)$ & 0.926 \\
\hline Hemopericardium & $19(16.52 \%)$ & $0.98(0.37,2.63)$ & 0.969 \\
\hline BUN (mmol/L) & $7.2 \pm 2.5$ & $1.03(0.89,1.19)$ & 0.722 \\
\hline Preoperative sCr (umol/L) & $86.2 \pm 29.07$ & $1.01(1.00,1.02)$ & 0.147 \\
\hline $\mathrm{eGFR} \mathrm{mL} /\left(\min \cdot 1.73 \mathrm{~m}^{2}\right)$ & $88.6 \pm 22.6$ & $0.98(0.96,1.00)$ & 0.013 \\
\hline Hemoglobin (g/L) & $136.5 \pm 17.3$ & $1.00(0.97,1.02)$ & 0.686 \\
\hline Hematocrit (\%) & $39.4 \pm 4.6$ & $0.97(0.89,1.05)$ & 0.440 \\
\hline LVEF (\%) & $62.9 \pm 6.1$ & $1.03(0.97,1.10)$ & 0.354 \\
\hline Renal artery dissection or occlusion & $17(14.8 \%)$ & $0.57(0.20,1.62)$ & 0.292 \\
\hline \multicolumn{4}{|l|}{ Penn class } \\
\hline Class Aa & $70(60.9 \%)$ & 1.0 & \\
\hline Non class Aa & $45(39.1 \%)$ & $1.18(0.56,2.50)$ & 0.665 \\
\hline Kidney malperfusion & $7(6.1 \%)$ & $1.19(0.25,5.59)$ & 0.823 \\
\hline AMl & $9(7.8 \%)$ & $3.37(0.67,16.98)$ & 0.141 \\
\hline Preoperative shock & $19(16.5 \%)$ & $0.98(0.37,2.63)$ & 0.969 \\
\hline CPB time & $211 \pm 56$ & $1.09(1.01,1.17)$ & 0.032 \\
\hline Aortic cross clamp time (min) & $123.8 \pm 42.6$ & $1.00(0.99,1.01)$ & 0.401 \\
\hline Bentall+TAR+FET & $47(40.9 \%)$ & $1.01(0.48,2.13)$ & 0.979 \\
\hline Combined with CABG & $8(7.0 \%)$ & $1.52(0.35,6.67)$ & 0.581 \\
\hline Combined with aortic bypass surgery & $1(0.9 \%)$ & a & 0.992 \\
\hline Circulatory arrest time (min) & $27.4 \pm 8.5$ & $1.00(0.96,1.05)$ & 0.913 \\
\hline Nasopharyngeal temperature $\left({ }^{\circ} \mathrm{C}\right)$ at circulatory arrest & $22.9 \pm 1.6$ & $0.83(0.65,1.06)$ & 0.143 \\
\hline Rectal temperature $\left({ }^{\circ} \mathrm{C}\right)$ at circulatory arrest & $25.3 \pm 2.1$ & $0.92(0.77,1.10)$ & 0.356 \\
\hline Intraoperative transfusion of PRBCs & $73(63.5 \%)$ & $0.90(0.42,1.92)$ & 0.779 \\
\hline Reoperation for bleeding & $9(7.83 \%)$ & $8.00(0.97,66.21)$ & 0.054 \\
\hline
\end{tabular}

Results are expressed as $\mathrm{n}(\%)$ or mean $\pm \mathrm{SD}$ or median $[\mathrm{IQR}]$

$A K I$ acute kidney injury, $A D T I A D$ acute DeBakey Type I aortic dissection, $A M I$ acute myocardial infarction, $B M I$ body mass index, $B U N$ blood urea nitrogen, $C A B G$ coronary artery bypass grafting, CPB cardiopulmonary bypass, eGFR estimated glomerular filtration rate, FET frozen elephant trunk, TAR total arch replacement, $\angle V E F$ left ventricular ejection fraction, $P R B C s$ packed red blood cells, $s C r$ serum creatinine, $S D$ standard deviation, IOR interquartile range Bold value indicates significance at $p<0.05$

${ }^{\mathrm{a}}$ The result failed because of the small sample size

interaction with AKI among these groups. Stratified analysis was given in Fig. 3.

\section{Discussion}

In this retrospective cohort study of 115 patients who underwent emergent thoracic aortic surgery for ADTIAD, we found that the $\mathrm{CPB}$ time was an independent predictor of postoperative AKI $(\mathrm{OR}=1.171 ; 95 \% \mathrm{CI}: 1.002-1.368$; $P=0.047)$. A $10 \mathrm{~min}$ increase in $\mathrm{CPB}$ time was associated with a $17.1 \%$ higher risk of postoperative AKI. After PS matching was applied to adjust for the potential confounding factors, the results still remained statistic significant. Further confirming the relationship between $\mathrm{CPB}$ time and postoperative AKI and validates our hypothesis. Thus, we should improve surgical techniques in surgery as soon as possible to reduce CPB time.

There have been several studies on the risks of postoperative AKI in patients underwent aortic surgery. Mori $\mathrm{Y}$ 


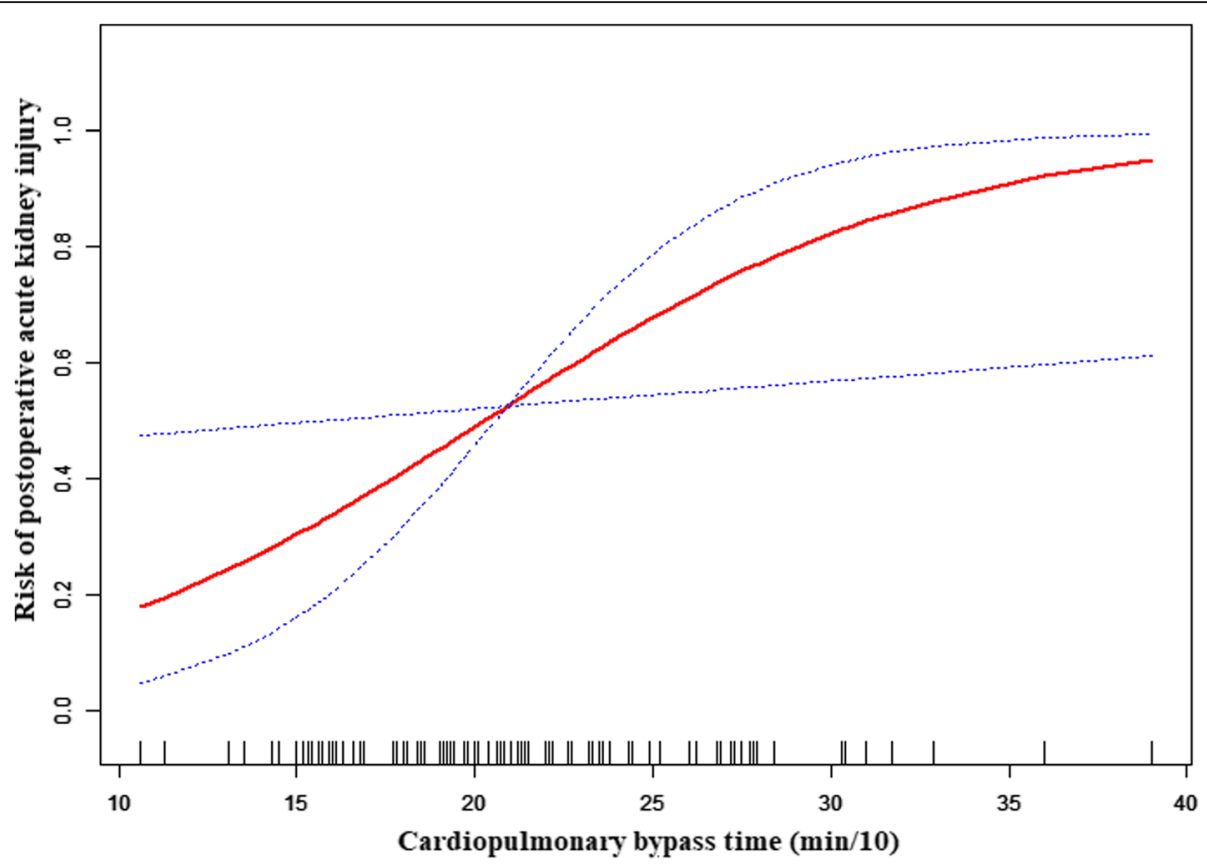

Fig. 2 A linear relationship between CPB time and postoperative AKI was observed. Adjusting for adjusted for age; gender; BMl; smoking history; aortic cross clamp time; nasopharyngeal temperature at circulatory arrest; combined with aortic bypass surgery; AMl; intraoperative transfusion of PRBCs; renal artery dissection or occlusion; Penn class; kidney malperfusion; preoperative shock; Bentall+TAR+FET. In this figure, the red line indicates the estimated risk of acute kidney injury, and the dotted lines represent pointwise $95 \% \mathrm{Cl}$

et al. [28] analyzed 135 patients who underwent aortic arch surgery under deep hypothermic circulatory arrest (DHCA). They found preoperative hypertension, emergency surgery and DHCA were associated with postoperative AKI. There were no differences in other characteristics, such as age, gender, BMI, duration of $\mathrm{CPB}$ time and aortic cross clamping time. The reason may be that the study population was different. A retrospective study included 737 patients who underwent aortic surgery with $\mathrm{CPB}$ by Kim WH et al. [17] they found the following variables were significantly associated with AKI after adjustment for other risk factors: age older than 60 years $(\mathrm{OR}=1.83,95 \% \mathrm{CI}: 1.13-2.96, P=$ 0.015), preoperative $\mathrm{GFR}<60 \mathrm{~mL} / \mathrm{min} \cdot 1.73 \mathrm{~m}^{2} \quad(\mathrm{OR}=$ 2.36, 95\% CI:1.40-3.96, $P=0.001)$, preoperative $\mathrm{LVEF}<$
$55 \%(\mathrm{OR}=2.08,95 \% \mathrm{CI}: 1.14-3.79, P=0.017)$, operation time $>7 \mathrm{~h}(\mathrm{OR}=2.63,95 \% \mathrm{CI}: 1.63-4.24, P<0.001)$ and intraoperative oliguria $(<0.5 \mathrm{~mL} / \mathrm{kg} / \mathrm{h})(\mathrm{OR}=2.81,95 \%$ CI: $1.37-5.77, P=0.005$ ) or intraoperative furosemide use $(\mathrm{OR}=1.99,95 \% \mathrm{CI}: 1.25-3.16, P=0.004)$. CPB time was not found to be association with postoperative AKI. The reason might be that they did not include the $\mathrm{CPB}$ time in the multivariate logistic regression equation although the baseline data of $\mathrm{CPB}$ time between non-AKI group and AKI group was different. Another study conducted by Kowalik MM et al. [19, 20], they reported that $\mathrm{CPB}$ time did not influence the development of postoperative AKI. These controversial results might be attributed to confounding factors in heterogeneous patient cohorts.

Table 3 Multivariable analysis to assess the independent impact of CPB time on postoperative AKI in patients with ADTIAD using none adjusted and fully adjusted logistic regression model

\begin{tabular}{|c|c|c|c|c|c|c|c|c|}
\hline Variable & $\begin{array}{l}\text { Model I } \\
\text { OR }(95 \% \mathrm{Cl})\end{array}$ & $P$-value & $\begin{array}{l}\text { Model II } \\
\text { OR }(95 \% \mathrm{Cl})\end{array}$ & $P$-value & $\begin{array}{l}\text { Model III } \\
\text { OR }(95 \% \mathrm{Cl})\end{array}$ & $P$-value & $\begin{array}{l}\text { Model IV } \\
\text { OR }(95 \% \mathrm{Cl})\end{array}$ & $P$-value \\
\hline CPB time (per $10 \mathrm{~min}$ ) & $1.085(1.007,1.170)$ & 0.033 & $1.092(1.012,1.179)$ & 0.024 & 1.166 (1.009-1.349) & 0.031 & $1.171(1.002-1.368)$ & 0.047 \\
\hline $\begin{array}{l}\text { AKI acute kidney injury, } \\
\text { cardiopulmonary bypass, } \\
\text { confidence interval } \\
\text { Model I: adjust for none } \\
\text { Model II: adjust for age; } \\
\text { Model III: adjust for age; } \\
\text { surgery; AMI; Intraoperati } \\
\text { Model IV: adjust for age; } \\
\text { surgery; AMI; Intraoperati }\end{array}$ & $\begin{array}{l}\text { DTIAD acute DeBakey T } \\
\text { FET frozen elephant tru } \\
\text { ender } \\
\text { yender; BMl; smoking hi } \\
\text { ve transfusion of PRBCs } \\
\text { gender; BMl; smoking } \mathrm{h}\end{array}$ & ory; aorti & cross clamp time; nas & taryngea & temperature at circula & y arrest; & ombined with aortic b & $\begin{array}{l}P B \\
95 \% \\
\\
\text { pass } \\
\text { pass }\end{array}$ \\
\hline
\end{tabular}




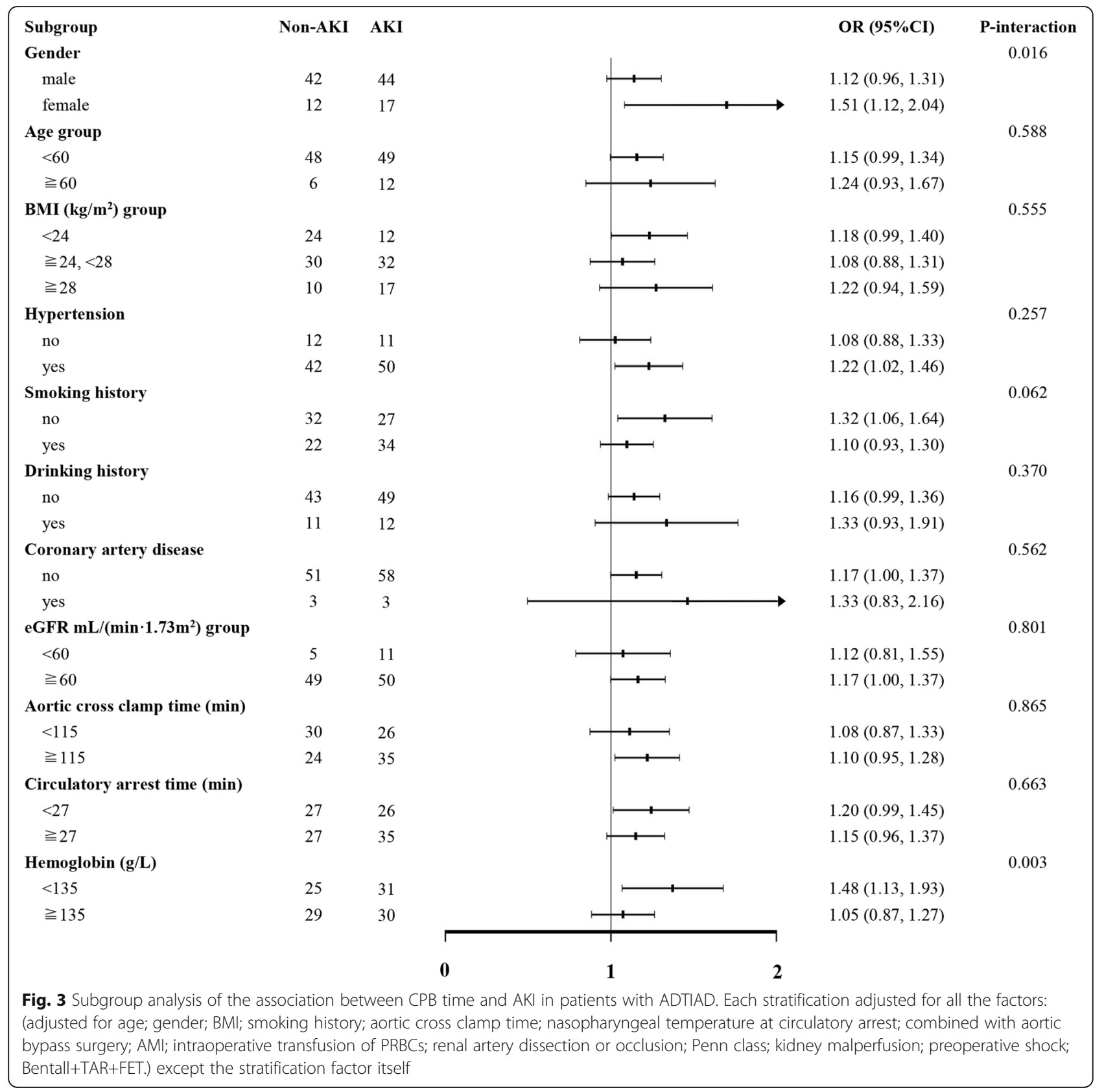

This result was consistent with what Englberger L et al. identified [22], they studied 851 patients who underwent elective thoracic aortic operation with and without DHCA, and postoperative AKI was defined by consensus RIFLE (Risk, Injury, Failure, Loss of function, End-stage renal disease) criteria. They found longer CPB time (per $10 \mathrm{~min}$ ) was a significantly risk factor of postoperative AKI (OR = 1.09, 95\% CI:1.05-1.12; P = 0.001). Roh GU et al. [32] analyzed 98 patients underwent graft replacement of the thoracic aorta in patients with aortic dissection, and they found long $\mathrm{CPB}$ duration ( $>180 \mathrm{~min}$; $\mathrm{OR}=7.50 ; P=0.008$ ) was an independent risk factor for postoperative AKI which was consistent with our study. Geoge J et al. [3] analyzed 586 patients who undergoing elective aortic hemiarch reconstruction, they also found CPB time ( $\mathrm{min})(\mathrm{OR}=1.01,95 \%$ CI: $1.00-1.01 ; P=0.03)$ was an independent risk factor of postoperative AKI. Moreover, several other studies [5, 13, $18,23,30$ ] had found that CPB time was an independent predictor of postoperative AKI in patients underwent cardiac and vascular surgery which further verified our findings.

The potential mechanism for this association between CPB time and AKI was unclear. Mamikonian et al. [27] investigated the association between hemolysis and 
postoperative AKI in 42 children who undergoing cardiac surgery with $\mathrm{CPB}$. They found that significant hemolysis occurred during $\mathrm{CPB}$ and was related to the development of postoperative AKI. Decreasing CPB-induced hemolysis or attenuating the effects of CPB-induced hemolysis by augmenting endogenous mechanisms that exist to scavenge and remove free hemoglobin may provide a way to more rapidly clear excess plasma free hemoglobin, decrease oxidant injury, and minimize the toxic effects of acute hemolysis and reduce the incidence of AKI. L. Lannemyr et al. [25] performed a detailed analysis on the association between the renal tubular injury and CPB. They found that a renal tubular cell injury was detected early after onset of CPB and with a peak biomarker increased early after the CPB during cardiac surgery. The magnitude of renal tubular injury was independently association with $\mathrm{CPB}$ duration and the degree of rewarming. The means to decrease the risk for tubular injury were decreasing the $\mathrm{CPB}$ duration and avoiding hypothermia.

The incidence of AKI after operation in our study was similar to that found in two former studies that used RIFLE criteria [1, 2, 14]. Hobson et al. [14] documented an incidence of AKI following aortic surgery of $55 \%$, which was comparable to our finds. Although there were little data concerning the patients' characteristics in that study, their study cohort was seemingly heterogeneous according to diagnosis and surgical condition. Another study recorded an AKI incidence rate of $48 \%$ in 267 patients following aortic arch surgery with DHCA, including 36\% of AAD and 36\% of emergency operations [1, 2]. However, Englberger et al. [10] recently showed a relatively low incidence rate of AKI (17.7\%) and RRT (2.1\%) among 851 patients who underwent elective thoracic aortic surgery with and without DHCA. In this study, both acute dissection and emergency surgery, which had been known independent predictors for postoperative AKI [12], were excluded. Considering that our study cohort underwent emergent aortic TAR combined with a FET implant as a result of ADTIAD, the incidence of AKI (53\%) was not surprising.

This study has several strengths. First, the patients selected for this study comprised a homogeneous population of patients with ADTIAD underwent urgent thoracic aortic surgery with moderate hypothermic circulatory arrest (HCA). Second, because the worst sCr level was available daily for all patients during the entire study period, AKI development could be assessed for all patients accurately. Finally, we adopted the KDIGO guidelines for AKI instead of the previous two classifications since the KDIGO guidelines have been revised most recently and offered clarity and simplicity in clinical use. Increased understanding of the predictors associated with AKI development is significant, and highlighting $\mathrm{CPB}$ as a risk factor may guide clinical management strategies intraoperatively which included improving surgical skills, operating as soon as possible and reducing $\mathrm{CPB}$ time.

\section{Study limitations}

Our research also has several limitations which are worth noting. First, it is a retrospective cohort study, and for this purpose, can constitute an association, but not a causality between CPB time and AKI. Second, aortic TAR combined with a FET implant is a preferred choice to treat ADTIAD at our center, while other centers may select more conventional procedures, this may result in a discrepancy in the outcomes among different studies, but our study cohort also forms a homogenous population who had undergone this procedure, which adds internal validity. Finally, nearly all patients were male in our cohort. Caution is required when extrapolating these findings to female patients.

\section{Conclusions}

$\mathrm{CPB}$ time is an independent predictor of postoperative AKI in patients underwent thoracic aortic surgery for ADTIAD. Further understanding of the molecular mechanism of this association is crucial to the design of preventative therapies.

\section{Additional files}

Additional file 1: Figure S1. PS matching method was used to adjust intergroup differences between AKI and non-AKI group. We calculated the PS for each patient by matching variable (age; gender; BMl; diabetes mellitus; hypertension; smoking history; $\mathrm{BUN}$; preoperative $\mathrm{s} C \mathrm{r}$;

hemoglobin; hematocrit; eGFR). (TIF $23 \mathrm{~kb}$ )

Additional file 2: Table S1. Characteristics of the study patients at baseline after propensity score matching. (DOC $40 \mathrm{~kb}$ )

Additional file 3: Table S2. Multivariable analysis to assess the independent impact of CPB time on postoperative AKI in patients with ADTIAD after PSM. (DOC $33 \mathrm{~kb}$ )

\section{Abbreviations}

ACT: Activated clotting time; ADTIAD: Acute DeBakey Type I aortic dissection; AKI: Acute kidney injury; AKIN: Acute Kidney Injury Network; AMI: Acute myocardial infarction; BMI: Body mass index; BUN: Blood urea nitrogen; CABG: Coronary artery bypass grafting; CAG: Coronary angiography; Cl: Confidence interval; CPB: Cardiopulmonary bypass; DHCA: Deep hypothermic circulatory arrest; GAM: Generalized additive model; HCA: Hypothermic circulatory arrest; ICU: Intensive care unit; KDIGO: Kidney Disease Improving Global Outcomes; LVEF: Left ventricular ejection fraction; OR: Odds ratio; PRBCs: Packed red blood cells; PS: Propensity score; RIFLE: Risk, Injury, Failure, Loss and End-stage; RRT: Eenal replacement therapy; SCP: Selective cerebral perfusion; sCr: Serum creatinine; SD: Standard deviation

\section{Acknowledgments}

We would gratefully thank Dr. Xinglin Chen and Dr. Chi Chen of the Department of Epidemiology and Biostatistics, X\&Y solutions Inc. in Boston for their contribution to the statistical support.

\section{Funding}

This study was supported by National Key R\&D Program of China (2017YFC1308000), The Capital Health Research and Development of Special 
(2018-2-2-66), the National Science Foundation of China (81600362), Beijing Municipal Administration of Hospitals' Youth Program: QML20170602 and the Beijing Lab for Cardiovascular Precision Medicine, Beijing, China. PXM2017_014226_000037.

\section{Availability of data and materials}

The datasets used or analyzed during the current study are available from the corresponding author on reasonable request.

\section{Authors' contributions}

SJX, MG, HJZ designed the study; XLG, LL, ZNW, JCL collected the data; SJX $J L$ analyzed the data; SJX analyzed and interpreted the results; $Y M L, J M Z$ and LZS support and encourage the study; SJX wrote this article; All the authors have read and reviewed this manuscript.

\section{Ethics approval and consent to participate}

The study protocol was approved by the ethics committee at Anzhen Hospital (Institutional Review Board File 2014019), and all experimental methods were performed in accordance with the relevant guidelines and regulations.

\section{Consent for publication}

Consent was obtained from the patients or their relatives.

\section{Competing interests}

The authors have declared that no interest.

\section{Publisher's Note}

Springer Nature remains neutral with regard to jurisdictional claims in published maps and institutional affiliations.

\section{Author details}

${ }^{1}$ Department of Cardiac Surgery, Beijing Aortic Disease Center, Beijing Anzhen Hospital, Capital Medical University, Beijing Institute of Heart Lung and Blood Vessel Diseases, Beijing Lab for Cardiovascular Precision Medicine, and Beijing Engineering Research Center of Vascular Prostheses, No.2 Anzhen Street, Beijing 100029, China. ${ }^{2}$ Department of Vascular and Endovascular Surgery, Chinese PLA General Hospital, Beijing 100853, China.

\section{Received: 12 February 2019 Accepted: 22 April 2019}

\section{Published online: 07 May 2019}

\section{References}

1. Arnaoutakis GJ, Bihorac A, Martin TD, et al. RIFLE criteria for acute kidney injury in aortic arch surgery. J Thorac Cardiovasc Surg. 2007a;134:15541560-60-1561.

2. Arnaoutakis GJ, Bihorac A, Martin TD, et al. RIFLE criteria for acute kidney injury in aortic arch surgery. J Thorac Cardiovasc Surg. 2007b;134:1554-61.

3. Arnaoutakis GJ, Vallabhajosyula P, Bavaria JE, et al. The impact of deep versus moderate hypothermia on postoperative kidney function after elective aortic Hemiarch repair. Ann Thorac Surg. 2016;102:1313-21.

4. Austin PC. A comparison of 12 algorithms for matching on the propensity score. Stat Med. 2014;33:1057-69.

5. Berg KS, Stenseth R, Wahba A, et al. How can we best predict acute kidney injury following cardiac surgery? Eur J Anaesth. 2013;30:704-12.

6. Bove $\mathrm{T}$, Calabro MG, Landoni $\mathrm{G}$, et al. The incidence and risk of acute renal failure after cardiac surgery. J Cardiothorac Vasc Anesth. 2004;18:442-5.

7. Chien T, Wen H, Huang J, et al. Significance of preoperative acute kidney injury in patients with ADTIAD. J Formos Med Assoc. 2018.

8. Collins JS, Evangelista A, Nienaber CA, et al. Differences in clinical presentation, management, and outcomes of ADTIAD in patients with and without previous cardiac surgery. Circulation. 2004;110:1237-42.

9. D'Onofrio A, Cruz D, Bolgan I, et al. RIFLE criteria for cardiac surgeryassociated acute kidney injury: risk factors and outcomes. Congest Heart Fail. 2010;16(Suppl 1):S32-6.

10. Englberger L, Suri RM, Greason KL, et al. Deep hypothermic circulatory arrest is not a risk factor for acute kidney injury in thoracic aortic surgery. J Thorac Cardiovasc Surg. 2011;141:552-8.

11. Feier $H$, Cozma D, Sintean M, et al. How much Malperfusion is too much in ADTIADs? J Clin Med. 2019;8:304.
12. Geirsson A, Szeto WY, Pochettino A, et al. Significance of malperfusion syndromes prior to contemporary surgical repair for acute type a dissection: outcomes and need for additional revascularizations. Eur J Cardiothorac Surg. 2007;32:255-62.

13. Heringlake M, Charitos El, Erber K, et al. Preoperative plasma growthdifferentiation factor-15 for prediction of acute kidney injury in patients undergoing cardiac surgery. Crit Care. 2016;20:317.

14. Hobson CE, Yavas S, Segal MS, et al. Acute kidney injury is associated with increased long-term mortality after cardiothoracic surgery. Circulation. 2009; 119:2444-53.

15. Kellum JA, Lameire N. Diagnosis, evaluation, and management of acute kidney injury: a KDIGO summary (part 1). Crit Care. 2013;17:204.

16. Kernan WN, Viscoli CM, Brass LM. Phenylpropanolamine and the risk of hemorrhagic stroke. N Engl J Med. 2000;343:1826-32.

17. Kim WH, Lee SM, Choi JW, et al. Simplified clinical risk score to predict acute kidney injury after aortic surgery. J Cardiothor Vasc An. 2013;27:1158-66.

18. Ko TM, Higashitani MMP, Sato AM, et al. Impact of acute kidney injury on early to long-term outcomes in patients who underwent surgery for type a acute aortic dissection. Am J Cardiol. 2015;116:463-8.

19. Kowalik MM, Lango R, Klajbor K, et al. Incidence- and mortality-related risk factors of acute kidney injury requiring hemofiltration treatment in patients undergoing cardiac surgery: a single-center 6-year experience. J Cardiothorac Vasc Anesth. 2011a;25:619-24.

20. Kowalik MM, Lango R, Klajbor K, et al. Incidence- and mortality-related risk factors of acute kidney injury requiring hemofiltration treatment in patients undergoing cardiac surgery: a single-center 6-year experience. J Cardiothor Vasc An. 2011 b;25:619-24.

21. Kuitunen A, Vento $A$, Suojaranta-Ylinen $R$, et al. Acute renal failure after cardiac surgery: evaluation of the RIFLE classification. Ann Thorac Surg. 2006;81:542-6.

22. Kumar ABMF, Bridget Zimmerman MP, Suneja MM. Obesity and postcardiopulmonary bypass-associated acute kidney injury: a single-center retrospective analysis. J Cardiothor Vasc An. 2014a;28:551-6.

23. Kumar ABMF, Bridget Zimmerman MP, Suneja MM. Obesity and postcardiopulmonary bypass-associated acute kidney injury: a single-center retrospective analysis. J Cardiothor Vasc An. 2014b;28:551-6.

24. Lameire N, Kellum JA. Contrast-induced acute kidney injury and renal support for acute kidney injury: a KDIGO summary (part 2). Crit Care. 2013; 17:205.

25. Lannemyr $L$, Lundin $E$, Reinsfelt $B$, et al. Renal tubular injury during cardiopulmonary bypass as assessed by urinary release of $\mathrm{N}$-acetyl-ss-Dglucosaminidase. Acta Anaesthesiol Scand. 2017;61:1075-83.

26. Liu ZG, Sun LZ, Chang Q, et al. Should the "elephant trunk" be skeletonized? Total arch replacement combined with stented elephant trunk implantation for DeBakey type I aortic dissection. J Thorac Cardiovasc Surg. 2006;131:107-13.

27. Mamikonian LS, Mamo LB, Smith PB, et al. Cardiopulmonary bypass is associated with hemolysis and acute kidney injury in neonates, infants, and children*. Pediatr Crit Care Med. 2014;15:e111-9.

28. Mori Y, Sato N, Kobayashi Y, et al. Acute kidney injury during aortic arch surgery under deep hypothermic circulatory arrest. J Anesth. 2011;25:799-804.

29. Nadim MK, Forni LG, Bihorac A, et al. Cardiac and vascular surgery-associated acute kidney injury: the 20th international consensus conference of the ADQI (acute disease quality initiative) group. J Am Heart Assoc. 2018;7.

30. Ng RRG, Chew STHM, Liu WBH, et al. Identification of modifiable risk factors for acute kidney injury after coronary artery bypass graft surgery in an Asian population. J Thorac Cardiovasc Sur. 2014;147:1356-61.

31. Olsson C, Hillebrant C, Liska J, et al. Mortality in ADTIAD: validation of the Penn classification. Ann Thorac Surg. 2011;92:1376-82.

32. O'Sullivan KE, Byrne JS, Hudson A, et al. The effect of obesity on acute kidney injury after cardiac surgery. J Thorac Cardiovasc Surg. 2015;150:1622-8.

33. Patel HJ, Williams DM, Dasika NL, et al. Operative delay for peripheral malperfusion syndrome in ADTIAD: a long-term analysis. J Thorac Cardiovasc Surg. 2008;135:1288-96.

34. Roh GU, Lee JW, Nam SB, et al. Incidence and risk factors of acute kidney injury after thoracic aortic surgery for acute dissection. Ann Thorac Surg. 2012;94:766-71.

35. Rosner MH, Okusa MD. Acute kidney injury associated with cardiac surgery. Clin J Am Soc Nephrol. 2006;1:19-32.

36. Sinatra R, Melina G, Pulitani I, et al. Emergency operation for ADTIAD: neurologic complications and early mortality. Ann Thorac Surg. 2001;71:33-8. 
37. Sun L, Qi R, Zhu J, et al. Total arch replacement combined with stented elephant trunk implantation: a new "standard" therapy for type a dissection involving repair of the aortic arch? Circulation. 2011;123:971-8.

38. Tsai HS, Tsai FC, Chen YC, et al. Impact of acute kidney injury on one-year survival after surgery for aortic dissection. Ann Thorac Surg. 2012;94:1407-12.

39. von Elm E, Altman DG, Egger $\mathrm{M}$, et al. The strengthening the reporting of observational studies in epidemiology (STROBE) statement: guidelines for reporting observational studies. Int J Surg. 2014;12:1495-9.

40. Zhao H, Pan X, Gong Z, et al. Risk factors for acute kidney injury in overweight patients with ADTIAD: a retrospective study. J Thorac Dis. 2015; 7:1385-90.

Ready to submit your research? Choose BMC and benefit from:

- fast, convenient online submission

- thorough peer review by experienced researchers in your field

- rapid publication on acceptance

- support for research data, including large and complex data types

- gold Open Access which fosters wider collaboration and increased citations

- maximum visibility for your research: over $100 \mathrm{M}$ website views per year

At $\mathrm{BMC}$, research is always in progress.

Learn more biomedcentral.com/submissions 